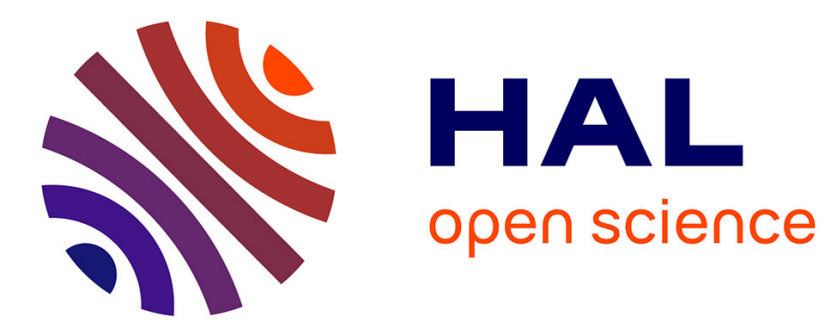

\title{
Mixed mode fracture of some tropical species with the grid method
}

Bernard Odounga, Moutou Pitti Rostand, Evelyne Toussaint, Michel Grédiac

\section{To cite this version:}

Bernard Odounga, Moutou Pitti Rostand, Evelyne Toussaint, Michel Grédiac. Mixed mode fracture of some tropical species with the grid method. Engineering Fracture Mechanics, 2019, 214, pp.578 589. 10.1016/j.engfracmech.2019.04.018 . hal-03484372

\section{HAL Id: hal-03484372 \\ https://hal.science/hal-03484372}

Submitted on 20 Dec 2021

HAL is a multi-disciplinary open access archive for the deposit and dissemination of scientific research documents, whether they are published or not. The documents may come from teaching and research institutions in France or abroad, or from public or private research centers.
L'archive ouverte pluridisciplinaire HAL, est destinée au dépôt et à la diffusion de documents scientifiques de niveau recherche, publiés ou non, émanant des établissements d'enseignement et de recherche français ou étrangers, des laboratoires publics ou privés.

\section{다)(1) $(5$}

Distributed under a Creative Commons Attribution - NonCommerciall 4.0 International 


\title{
Mixed mode fracture of some tropical species with the grid method
}

\author{
Bernard Odounga ${ }^{\mathrm{a}, \mathrm{b}}$, Rostand Moutou Pitti ${ }^{\mathrm{a}, \mathrm{c}}$, Evelyne Toussaint ${ }^{\mathrm{a}}$, Michel Grédiac ${ }^{\mathrm{a}}$, \\ ${ }^{a}$ Université Clermont Auvergne, CNRS, Institut Pascal, F-63000 Clermont-Ferrand, France \\ ${ }^{b}$ Université des Sciences et Techniques de Masuku, BP 901, Franceville, Gabon \\ ${ }^{c}$ CENAREST, IRT, BP. 14070, Libreville, Gabon
}

\begin{abstract}
The aim of this paper is to study the mixed-mode cracking of three tropical species of the Gabonese forest, namely iroko (Milicia Excelsa), okume (Aucoumea klaineana Pierre), and padouk (Pterocarpus soyauxii). The cracking tests were performed using MMCG (Mixed Mode Crack Growth) wood specimens. These tests were carried out in a temperaturecontrolled room, on specimens featuring two different thicknesses $b=12.5 \mathrm{~mm}$ and 15 $\mathrm{mm}$. The specimens were rotated with respect to the loading direction by using a suitable Arcan fixture. Three angles were considered $\alpha=15 \mathrm{deg}, 30 \mathrm{deg}$ and $45 \mathrm{deg}$. For all the specimens, the initial crack length was oriented along the fiber direction (RL). A full-field measurement technique, namely the grid method, was used to obtain the displacement and strain maps during the tests. The opening and the propagation of the crack tip were deduced from these maps. After decoupling the two modes involved during the tests (modes 1 and 2), the experimental energy release rates $G_{I}$ and $G_{I I}$ were evaluated with the imposed displacement compliance method. The results show the predominance of mode 1 over mode 2 . The contribution of mode 1 also decreases whereas that of mode 2 increases as the angle increases. The experimental results also show that the failure parameters of the species studies here are globally proportional to their density. The $G_{I} / G_{I I}$ ratio has also been calculated for okume, and it has been observed to be constant. This suggests that the values obtained during this study are values which are intrinsic to the species.
\end{abstract}

Keywords: Tropical woods, fracture analysis, MMCG and CTS specimens, grid method, iroko, okume, pakouk.

Email address: Rostand.Moutou_Pitti@uca.fr (Rostand Moutou Pitti ) 


\section{Introduction}

It is well known that the use of wood, wood products and timber structures, is one of the solutions that durably limit the global warming of our planet. In Central Africa and especially in equatorial regions, the forest plays a key role in this regulation. Concerning Gabon, which represents the world's leading producer of tropical wood, the forest covers more than $85 \%$ of the territory. This forest plays an important role in the economy of the country [1]. It is therefore of prime importance to characterize the mechanical behavior of the tropical species growing in these forests in order to use them optimally. The mechanical behavior of tropical species depends of various parameters. The main ones are (i) the temperature and humidity [2], (ii) their heterogeneity, which can be significant, (iii) the randomness of the orientation of the annual rings due to the continuous growth of these species, (iv) the variability of the density or defects such as knot densities. All these parameters can impair the efficiency of structures made of such species, and may potentially induce sudden failure during their service life. Investigating the complex fracture process in such of species is therefore an important challenge in the mechanical community of wood.

A literature review shows that some studies have been performed in mixed mode fracture on temperate species. Among them, Valentin [3] proposed the Compact Tension Shear (CTS) specimen designed by Richard (1983) to identify mixed mode in orthotropic materials like wood. Oliveira [4] used Double Cantilever Beam (DCB), Single Edge Notched Tensile (SENT) and the Wedge Splintting(WS) specimen in Maritime Pine. The obtained results enabled the authors to separate the energy release rates in opening and shear modes. Phan et al. [5] performed studies in mixed mode on Spruce, which has the same density as Okume, by combining numerical and experimental results. The invariant integral [6] has also been adapted to orthotropic materials by Moutou et al. [7] in order to estimate the contribution of each failure mode to the failure of the specimen. It is shown that the GI/GII ratio is favorable to mode II for values of small crack increments (typically $10 \mathrm{~mm}$ ). Beyond this value, this ratio is constant and the part of the opening mode becomes greater than mode 2 .

Yoshihara [8] performed mixed-mode on DCB specimens of Spruce to evaluate toughness in modes I and II. Other authors also studied the mixed mode configuration on wood $[9,10]$, but all these studies concern tempered species. In addition, these speci- 
mens do not ensure the crack growth stability in mixed mode configurations. In order to solve this problem, Moutou et al. $[11,12]$ proposed a suitable specimen, namely the Mixed-Mode Crack Growth (MMCG) specimen. This specimen is a compromise between the modified DCB specimen and the Compact Tension Shear specimen (CTS). It is especially suited to study the effect of creep on cracking in mixed mode. However, few works aimed at studying fracture mechanics of tropical species with the aforementioned specimen geometries [13].

In this context, the objective of this study is to investigate the mixed-mode cracking of tropical species of the Gabonese forest. As such, it can be considered as a follow-up of Ref.[14], where only the opening mode was studied. MMCG test specimens made of iroko, okume and padouk are considered here. Various thicknesses and mixed mode ratios are considered. The paper is organized as follows. The material and methods used in this study as well as the experimental device are first presented. In particular, we employed here a full-field measurement technique to characterize crack propagation, thus the basics of this technique are briefly recalled. The results obtained in terms of displacement maps and force as a function of the opening of the crack are then discussed. A decoupling method is applied to obtain the contribution of modes 1 and 2. The energy release rates of these species are calculated for modes 1 and 2 by applying a suitable decoupling method. These quantities are given as function of the crack length, the mixed mode ratio and the density.

\section{Materials and method}

\subsection{Wood specimens}

Heavy rains in equatorial and tropical areas mean that trees grow continuously throughout the year. Unlike temperate trees, which grow during marked seasons, it is very difficult to distinguish spring and summer woods in tropical woods. Indeed, Fahn [15] cited by Alvim [16], explains that only $35 \%$ of the tropical species have visible rings. This difficulty in distinguishing dark circles led to a rigorous selection of the blocks of wood to be machined in the present study, see figure 1. The wood blocks were cut in Gabon, about one meter above the roots of the standing tree. These blocks remained for about a month under local tropical and equatorial climatic conditions. They were shiped to Aubière, France, machined and kept under controlled temperature and relative humidity 
conditions (temperature $T: 21 \mathrm{deg} \mathrm{C} \pm 1 \mathrm{deg} \mathrm{C}$, and relative humidity $H R: 60 \% \pm 1 \%$ ). All the specimens were oriented along the grain direction (see the direction of the blue arrow in Figure 1). Three species were studied here, namely okume, iroko and padouk. It is worth mentioning that these species are widely used in various types of applications, in building construction, furniture or paper. However, apart from [17, 14], there is no paper available in the literature in which the mechanical properties of such species is discussed. The three species under study also have different densities, which is important because this parameter is known to influence the fracture properties of wood. Okume belongs to the category of very light wood (density: $0.44 \mathrm{E}+03 \mathrm{~kg} / \mathrm{m}^{3}$ ). This species has a light red color, which tends to whiten once dry. The trunk can reach between 0.6 and $2.0 \mathrm{~m}$ in diameter. Iroko is classified as light and medium heavy (density $0.64 \mathrm{E}+03 \mathrm{~kg} / \mathrm{m}^{3}$ ). It is yellow-brown in color with golden highlights. Its grain is coarse and its diameter can reach 0.8 to $1.0 \mathrm{~m}$. Finally, padouk belongs to the heavy and medium weight categories (density $0.79 \mathrm{E}+03 \mathrm{~kg} / \mathrm{m}^{3}$ ). Padouk is red. Its grain is coarse and the diameter of the trunk lies between 0.6 and $1.0 \mathrm{~m}$. Figure 1 shows typical blocks and specimens for these three species.
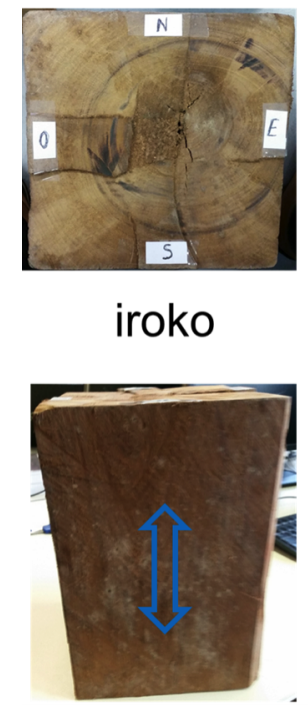

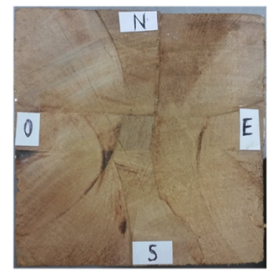

okume

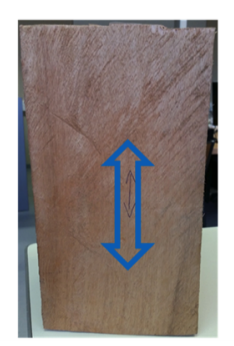

Figure 1: From wooden blocks to specimens

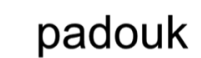

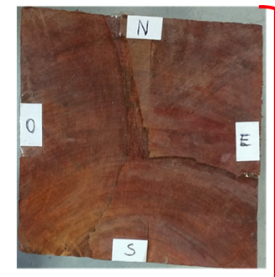
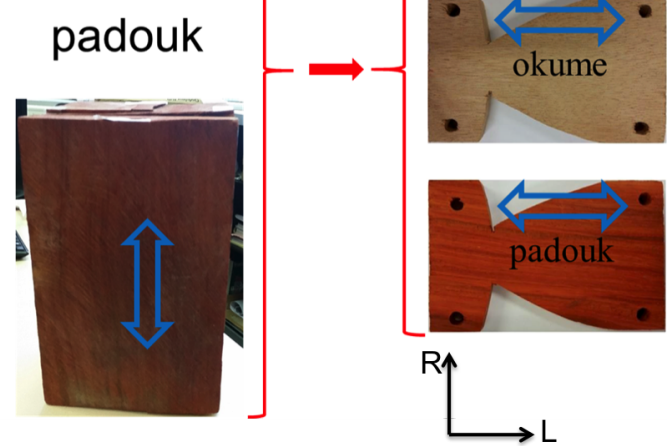

The moisture content $(M C)$ of the specimens is given in Table 1. This quantity is found with the following formula: 


$$
M C(\%)=\frac{m_{S}-m_{0}}{m_{0}} \times 100 \%
$$

where $m_{S}$ is the original mass and $m_{0}$ the mass of the oven-dried specimen. The specimens were therefore weighted first to obtain the wet mass denoted $m_{S}$. They were then placed in a furnace set at a temperature of $110 \operatorname{deg} \mathrm{C}$ to determine the dry mass $m_{0}$. The standardized temperature is $103 \mathrm{deg} \mathrm{C}$ [18]. The temperature used here is in this range. The specimens remained in the oven until the mass had completely stabilized for 4 days. The specimens were weighed three times a day to check whether their weight had stabilized before making the calculations. This value of the internal humidity was obtained in two ways, by calculation (with equation 1) and by direct measurement with a Merlin 60-HMEvo 25 moisture meter. The other values of the mechanical properties of the species under study are given here as an indication. They are available in [19].

Table 1: Mechanical characteristics of the three species under study. MOE: longitudinal modulus of elasticity, MC: moisture content, CSR: compression stress of rupture, CRFS: static bending failure stress, SD: standard deviation.

\begin{tabular}{cccc}
\hline $\begin{array}{c}\text { Wood } \\
\text { Species }\end{array}$ & $\begin{array}{c}\text { Aucoumea klaineana } \\
\text { or okume (SD) }\end{array}$ & $\begin{array}{c}\text { Milicia excelsa } \\
\text { or iroko (SD) }\end{array}$ & $\begin{array}{c}\text { Pterocarpus soyauxii } \\
\text { or padouk (SD) }\end{array}$ \\
\hline Density $\left(1 \mathrm{E}+03 \mathrm{~kg} / \mathrm{m}^{3}\right)$ & $0.44(0.06)$ & $0.64(0.06)$ & $0.79(0.09)$ \\
\hline $\mathrm{MOE}(\mathrm{MPa})$ & $9690(1231)$ & $12840(2496)$ & $15870(1885)$ \\
\hline $\mathrm{MC}(\%)$ & 9.12 & 7.94 & 7.29 \\
\hline $\mathrm{CSR}(\mathrm{MPa})$ & $36(5)$ & $54(6)$ & $65(8)$ \\
\hline $\mathrm{CRFS}(\mathrm{MPa})$ & $62(11)$ & $87(15)$ & $116(24)$ \\
\hline
\end{tabular}

\subsection{Wood modified MMCG specimens}

The dimensions of the modified MMCG specimens are given in Figure 2. $\alpha$ (deg) represents the mixed mode ratio and $b(\mathrm{~mm})$ the thickness of the specimen, see Table 2 notch was machined in all the specimens. A small crack (about $2 \mathrm{~mm}$ in length) was made by hand with a cutter at the tip of the notch in order to initiate the crack along a well-controlled direction. The initial length of the notch and this crack was $a_{i}=24 \mathrm{~mm}$ for $\alpha=15 \mathrm{deg}$ and $28 \mathrm{~mm}$ for $\alpha=30 \mathrm{deg}$ and $45 \mathrm{deg}$.

Table 2 gives the notation and the name of the MMCG specimens tested in this paper. Six specimens of three species were tested for $\alpha=15 \mathrm{deg}$ and $b=15 \mathrm{~mm}$ (two for each 


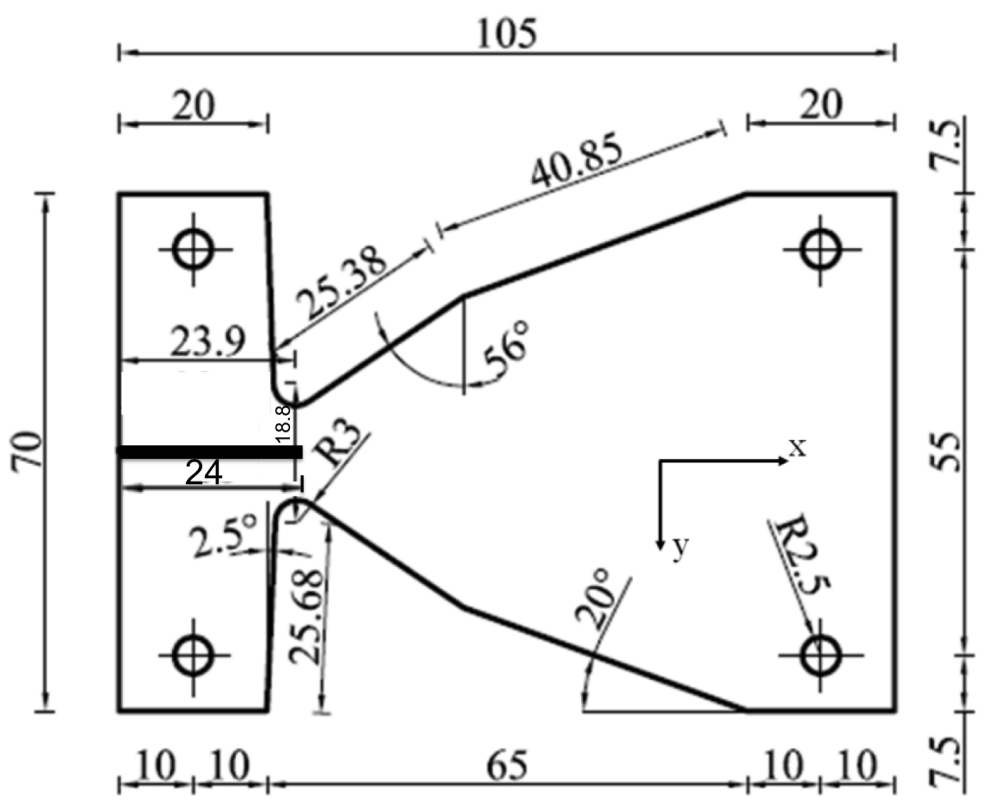

Figure 2: Dimensions of the modified MMCG specimen (in $\mathrm{mm}$ ). Note that depending on the specimens, the initial length of the crack is either equal to $24 \mathrm{~mm}$ or $28 \mathrm{~mm}$

species), seven okoume specimens were tested for $\alpha=30$ deg and $b=15 \mathrm{~mm}$ and six specimens were tested for $\alpha=45 \mathrm{deg}$ and $b=12.5 \mathrm{~mm}$ (two for each of the three species).

Table 2: Notations used in this study with: $\mathrm{O}=$ okume; $\mathrm{I}=$ iroko; $\mathrm{P}=$ padouk; $1,2,3, . .=$ test number for the MMCG specimen; 12.5, and $15=$ thickness of the specimens.

\begin{tabular}{lccc}
\hline Designation & $\begin{array}{c}\text { Milicia excelsa } \\
\text { (iroko) }\end{array}$ & $\begin{array}{c}\text { Aucoumea klaineana } \\
\text { (okume) }\end{array}$ & $\begin{array}{c}\text { Pterocarpus soyauxii } \\
\text { (padouk) }\end{array}$ \\
\hline Specimens tested at $15 \mathrm{deg}$ & $I_{2}(15)$ & $O_{1}(15)$ & $P_{1}(15)$ \\
\hline & & $O_{2}(15)$ & $\mathrm{P} 2(15)$ \\
Specimens tested at $30 \mathrm{deg}$ & & $O_{1}(15)$ & \\
\hline Specimens tested at $45 \mathrm{deg}$ & $I_{1}(12.5)$ & $O_{2}(15) / O_{3}(15)$ & \\
& $I_{2}(12.5)$ & $O_{4}(15) / O_{5}(15)$ & $P_{1}(12.5)$ \\
\hline
\end{tabular}

In fact, the fracture toughness increases as the thickness of the specimen increases. In 
this case, the crack growth process is observed with $\mathrm{b}=15 \mathrm{~mm}, \alpha=15$ and 30 deg only. For $\alpha=30$ and 45 , the thickness of the specimen is changed in order to avoid the sudden collapse of the specimens at the connexion level.

Figures 3 and 4 show two typical examples of tested specimens. Aluminium washers were bonded to reinforce the fastening holes. They limit the risk of early failure of the specimens in the connexion zone. The upper part of the specimens was reinforced with small aluminum plates for the same reason. An epoxy adhesive was used to bond the washers and the small plates. A grid was transferred on the surface of each specimen in order to determine the displacement fields. Depending on the species and on the specimen, the orientation of the fibers is more or less visible to the naked eye. Some deviation with the theoretical orientation of the fibers can also be observed. This is visible through the slight inclination of the fibers with respect to the orientation of the initial crack. The method used to obtain the displacement and strain fields from the grid images is described in the next section.

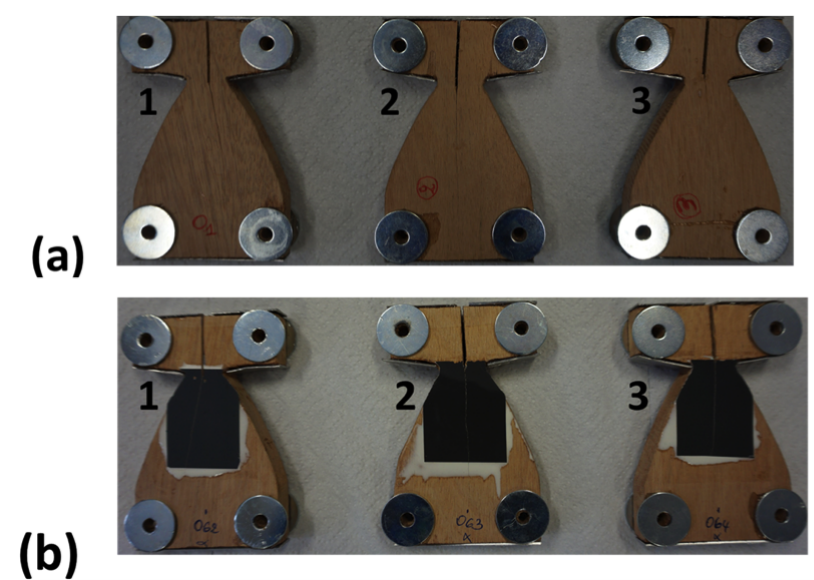

Figure 3: Typical MMCG specimens: (a) faces without grids (a) and (b) faces equipped with grids (for $\alpha=30 \mathrm{deg})$.

The Arcan test device described in Ref. [14] was used in this study. The geometry of the Arcan system is such that the test can be performed with different values of $\alpha$. Only results obtained for $\alpha$ lying between 0 and $45 \mathrm{deg}$ are given in this study. Results for higher values could not be obtained because in these cases, the specimens instantaneously failed. It is worth mentioning that in Ref. [12], experimental results for tempered species are also given for angles lying between 0 and $45 \mathrm{deg}$ only, as in the present paper. For tempered species and for higher values of the angle, the failure of the MMCG specimens immediately occurred near the connexions, just after starting the tests. To overcome 

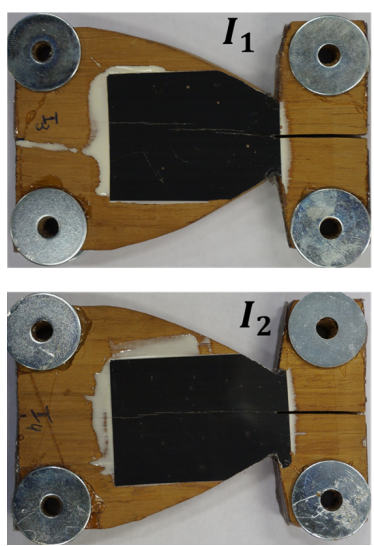
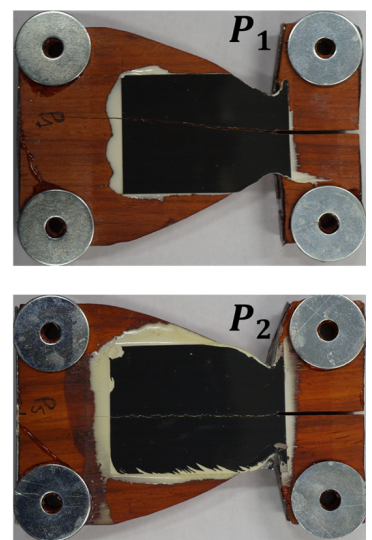

Figure 4: Typical MMCG specimens equiped with grids (for a mix angle $45 \mathrm{deg}$ ).

this issue, all mixed mode solicitations were performed after machining a new MMCG specimen by introducing a groove along the path of the crack propagation. This new geometry is described in Ref. [11] in the case of tempered species. However, such grooves could not be machined in the present study because of the limited number of specimens that were available.

\subsection{Grid method}

The grid method is a full-field measurement technique aimed at estimating in-plane displacement and strain fields. It consists first in depositing a regular pattern such as a bidimensional grid onto the surface of the specimen, for instance by using the procedure described in [20]. Images of this grid are taken while the specimen is subjected to a load and thus deforms. These images are then processed by using a Fourier-based technique in order to retrieve the displacement fields. The strain fields are deduced by differentiation. Full details on this technique can be found in [21]. This technique has already been successfully used to characterize crack opening in wood specimens, see [17, 14, 22] for instance. Indeed, it features a good compromise between noise level in the final displacement and strain maps on the one hand, and spatial resolution on the other hand, as discussed for instance in [23].

\subsection{Compliance Method}

In this study, the energy release rate $G$ of the three species was calculated by using the compliance method. The following equation was used for this calculation: 


$$
\left\{\begin{array}{l}
G_{I}=\frac{\left(F c_{x}\right)^{2}}{2 b} \times\left(\frac{\Delta C}{\Delta a}\right)_{d} \\
G_{I I}=\frac{\left(F c_{y}\right)^{2}}{2 b} \times\left(\frac{\Delta C}{\Delta a}\right)_{d}
\end{array}\right.
$$

where $G_{I}$ and $G_{I I}$ are the energy release rates in mode 1 and 2 , respectively. $F c_{i}$ $(i=x, y, z)$ is the so-called critical strength for which an increase $\Delta a$ of the crack length $a$ is obtained. $b$ is the thickness of the specimen. As a general remark, the compliance is defined by $\Delta C=U_{i} / F c_{i}$, where $U_{i}$ is the crack opening induced by each critical load $F c_{i}$. In Equation (2), $\Delta C$ is the increase in compliance corresponding to the increase in crack length $\Delta a$. Index $d$ used in Equation 2 means that the test is carried out with an imposed displacement. For the MMCG specimens, crack propagate stepwise, so we deal with the increments $\Delta C$ and $\Delta a$ between two stable configurations of the crack. It is worth noting that force changes are too small to be really observable to the naked eye in the curves representing the applied force as a function of the crack opening. These small drops are detected automatically by a in-house program described in [14]. The corresponding crack length increase is then deduced from the displacement maps, also by using the procedure described in [14].

\subsection{Experimental setup}

The experimental device consists of a $200 \mathrm{kN}$ Zwick/Roel tensile/compression testing machine (see Figure 5). A grid was deposited on each specimen. The latter was mounted in the fixture and uniformly illuminated in such a way that the images of the grid taken by the camera had a good contrast. A miniature Arcan steel fastening system was used to load the wood specimens. It is visible in this figure. The camera was fixed on a tripod in order to take stabilized grid images during the tests. The test machine, driven in imposed displacements, was equipped with a force sensor.

In mixed mode, the camera has the same inclination as that of the specimen shown in Figure 6. The values of the crack opening (displacement of the crack lips) are therefore directly obtained along the $\mathrm{x}$ - and $\mathrm{y}$ - axes. The value of the crack opening is merely obtained by subtracting, along each direction $x$ and $y$, the corresponding displacement measured on each side of the crack, at a distance equal to $0.6 \mathrm{~mm}$ from the crack lip in order to avoid any border effect in the displacement maps. The force is inclined with respect to the $\mathrm{x}$ - and $\mathrm{y}$ ) axes, and thus with respect to the crack. This force is then 


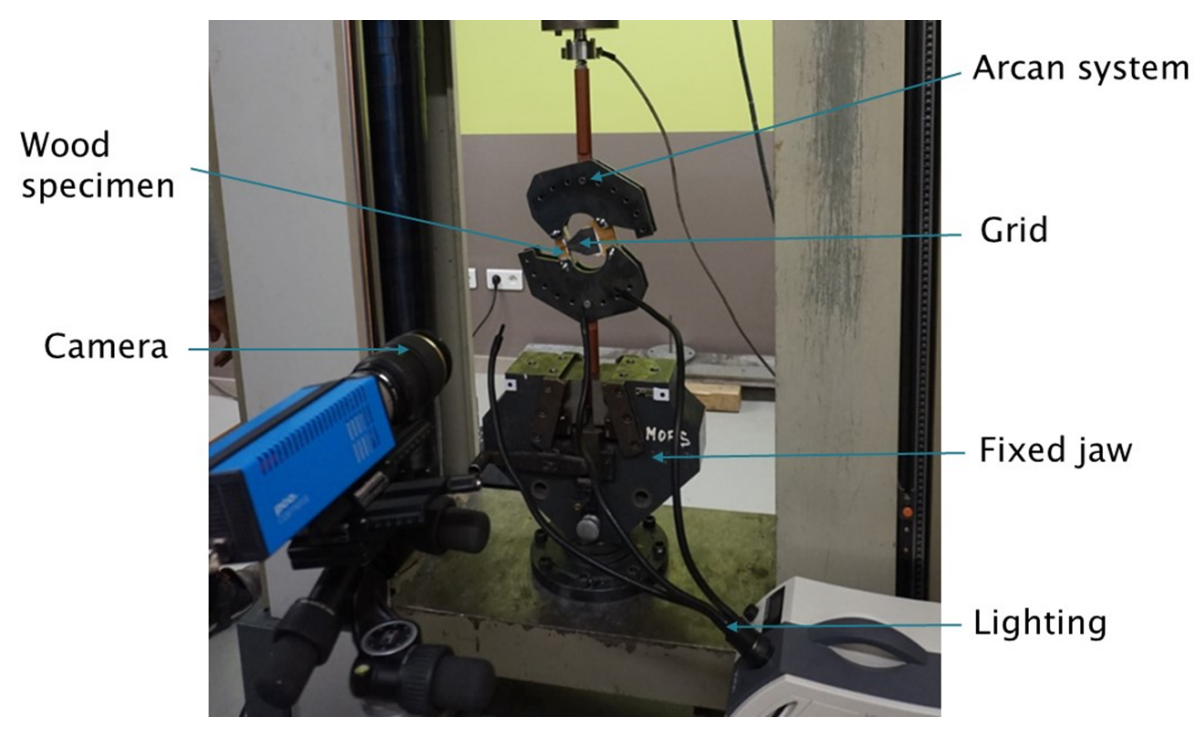

Figure 5: Experimental setup.

projected along $\mathrm{x}$ - and $\mathrm{y}$ - axes (see Figure 6). Obtaining $U, F$ and $a$ in the $\mathrm{x}$ - and $\mathrm{y}$ coordinate system makes it possible to use Equation 2 to obtain $G_{I}$ and $G_{I I}$, respectively.

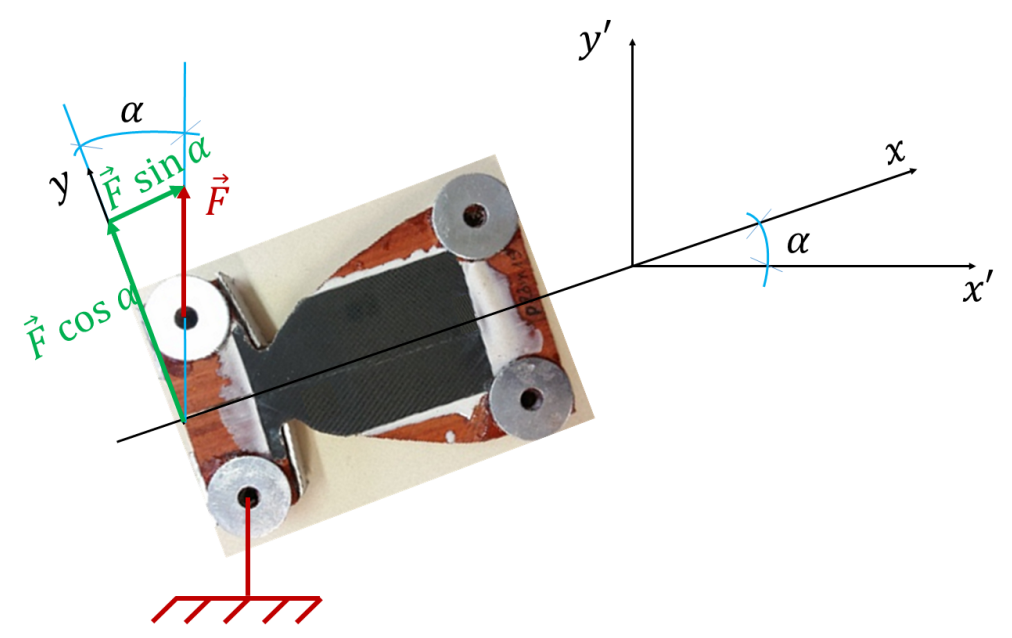

Figure 6: Projection of the strength following the $\mathrm{x}$ - and $\mathrm{y}$-axes

\section{Results and discussion}

The obtained results are presented here in terms of displacement maps and force/crack opening curves. The decoupling of the modes makes it possible to calculate the energy release rate for each mode. The energy release rate is given as a function of the crack length. The minimum average value of the energy release rate $G_{i c}$ is also given for each species and for each mode. For okume, the ratio $G_{I} / G_{I I}$ is given as a function of the 
crack length. The difference $G_{I}-G_{I I}$ also enables us to see the proportion of each mode and the fluctuation of the mixing rate.

\subsection{Displacement maps}

Some typical displacement maps $\left(U_{y}\right)$ are presented here for different mixed mode ratios $\alpha$. Figure 7-(a, b, c) shows some maps obtained for $\alpha=15 \mathrm{deg} / b=15 \mathrm{~mm}$, $\alpha=30 \mathrm{deg} / b=15 \mathrm{~mm}$ and $\alpha=45 \mathrm{deg} / b=12.5 \mathrm{~mm}$, respectively. In most cases, the crack evolution is like a horizontal straight line. However, in other cases, the profile is straight but it features a slight inclination with respect to the horizontal direction. Specimens $O_{1}$ and $\mathrm{O}_{4}$ in Figure 7-(b) are good illustrations of typical inclined crack propagation. This is often the case for tropical species because they feature a change of direction of the grain thread within the material. The property often leads to a high value of the energy release rate $G$.

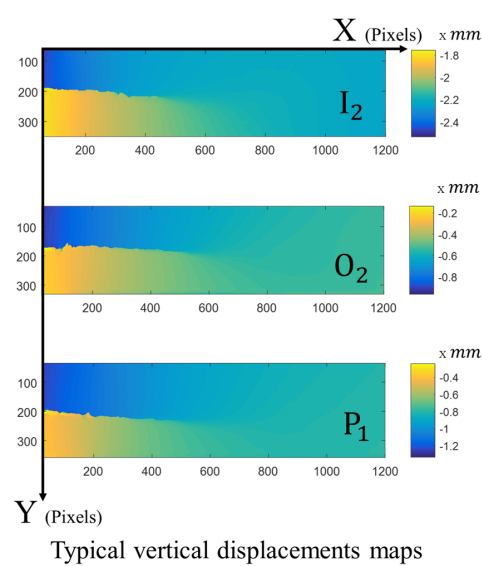

(a)

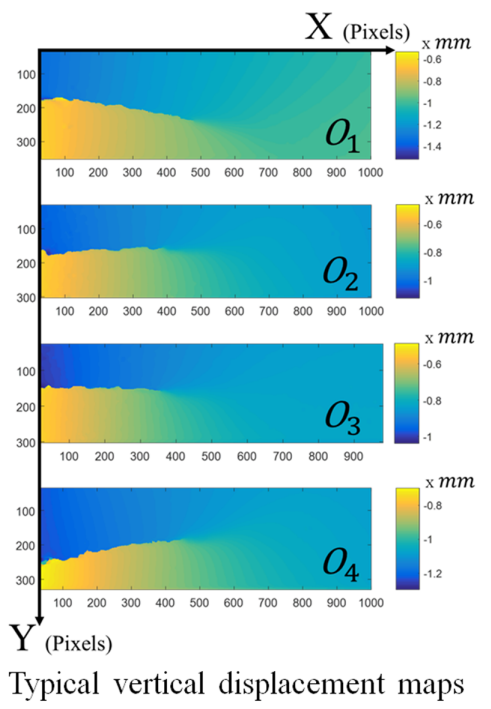

(b)

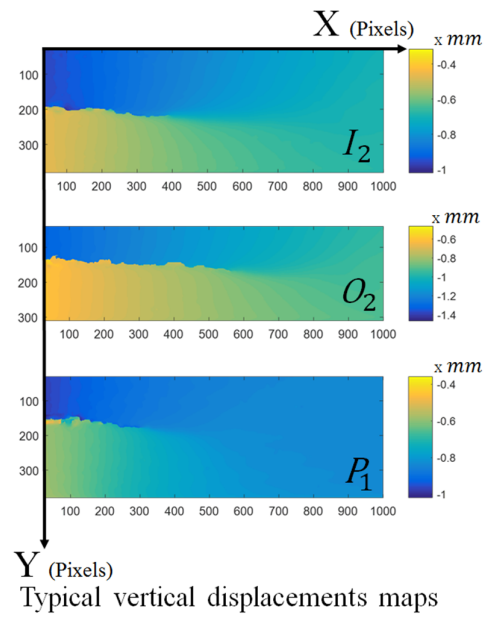

(c)

Figure 7: Typical displacement maps. (a) $\alpha=15 \mathrm{deg}, b=15 \mathrm{~mm}$. (b) $\alpha=30 \mathrm{deg}, b=15 \mathrm{~mm}$. (c) $\alpha=45 \mathrm{deg}, b=12.5 \mathrm{~mm}$.

\subsection{Load-Crack opening}

Figures 8-(a, b, c) represent the force vs. crack opening for $\alpha=15 \mathrm{deg} / b=15 \mathrm{~mm}$, $\alpha=30 \mathrm{deg} / b=15 \mathrm{~mm}$ and $\alpha=45 \mathrm{deg} / b=12.5 \mathrm{~mm}$, respectively. These quantities are given in the $\mathrm{x}$ - and $\mathrm{y}$ - directions. 


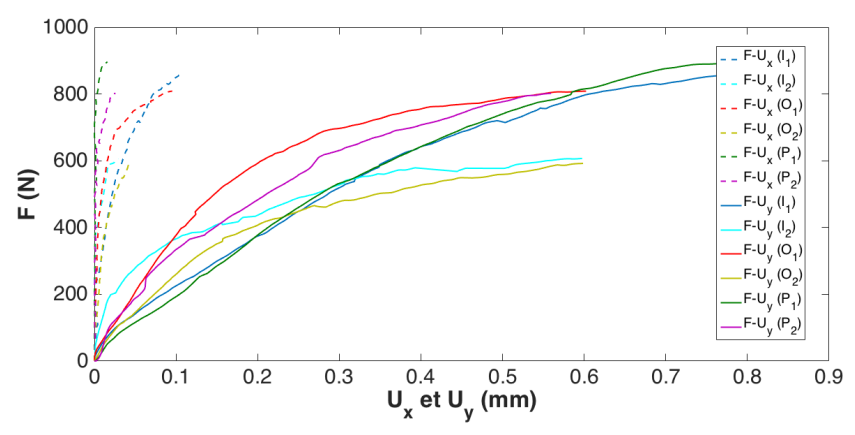

(a)

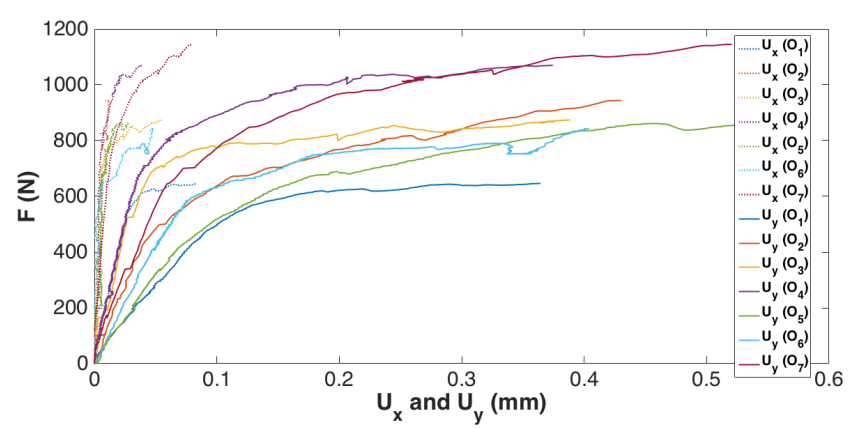

(b)

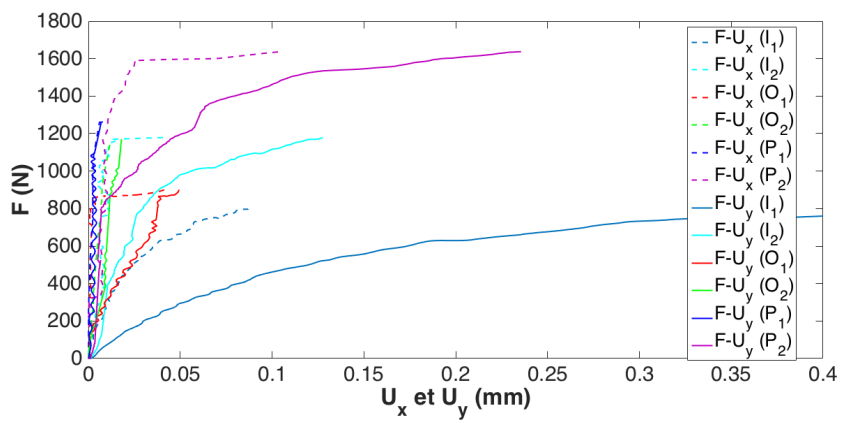

(c)

Figure 8: Force vs crack opening curves. (a) $\alpha=15 \mathrm{deg}, b=15 \mathrm{~mm}$. (b) $\alpha=30 \mathrm{deg}, b=15 \mathrm{~mm}$. (c) $\alpha=45 \operatorname{deg}, b=12.5 \mathrm{~mm}$.

The value of the crack opening along the $\mathrm{x}$-axis $x\left(U_{x}\right)$ is negligible compared to the one along the y-axis $\left(U_{y}\right)$. In Figure 8-(a) for example, the value of the crack opening along $x$ is lower than $0.1 \mathrm{~mm}$. The opening along $y$ is greater than along $x$ since it lies between 0.6 to $0.8 \mathrm{~mm}$. This difference decreases as $\alpha$ tends to $45 \mathrm{deg}$. In Figure 8-(c), we can see that the values of the crack openings $U_{x}$ and $U_{y}$ are lower than $0.3 \mathrm{~mm}$, except in one case. This illustrates that crack opening decreases with the increase of the mixing rate. In Figures 8, we can also notice that the force at failure increases as $\alpha$ increases. Indeed, in Figure 8-(a), failure occurs between $F=600$ and $900 N$, while this value lies 
between 600 and $1200 N$ in Figure 8-(b), and 600 and $1600 N$ in Figure 8-(c).

\subsection{Critical energy release rate}

The decoupling of the mixed modes is studied in this section. The energy release rates in opening mode $\left(G_{I}\right)$ and shear mode $\left(G_{I I}\right)$ are calculated with the compliance method in imposed displacement given by Equation 2. Figures 9, 10 and 11 represent $G_{I}$ and $G_{I I}$ as a function of the crack length for $\alpha=15,30$ and $45 \mathrm{deg}$, respectively. In these three figures, $G_{I}$ and $G_{I I}$ are plotted in subfigures (a) and (b), respectively. The first remark is that both $G_{I}$ and $G_{I I}$ increase as the crack length increases. Another remark is that in that $G_{I}>G_{I I}$ whatever the mixed mode ratio. Finally, the influence of the density of the species can be directly observed in Figures 9 and 11. Indeed, $G_{I}$ and $G_{I I}$ are greater for padouk than for iroko, and for iroko than for okume.

Figure 12 shows for both modes the mean minimum values $G_{i c}$ as well as its standard deviation. $G_{i c}$ is given here for $\alpha=45 \mathrm{deg}$ and $b=12.5 \mathrm{~mm}$, the values for the other mixed mode ratios and thicknesses being not available. We can note that both the mean value and the standard deviation are proportional to the density, which consistent with the remark above concerning Figures 9 and 11. The average value of $G_{i c}$ increases with the thickness of the specimen regardless of $\alpha$. The fracture toughness depends on the density of the specimen whatever the value of $\alpha$.

Let us now investigate the value of the $G_{I} / G_{I I}$ ratio. Indeed, this ratio is expected to be constant if $G_{I}$ and $G_{I I}$ are intrinsic values for each species. Figure 13 shows this ratio as a function of $a$ for okume. We can see that this ratio remains nearly constant as the crack propagates. This result is in agreement with the conclusion of [5]. This also illustrates the effectiveness of the procedure employed in this study.

Table 3 summarizes the comparison between the minimum energy release rate in opening mode $G_{i c 1}$ and its counterpart in shear mode $G_{i c 2}$ for $\alpha=15,30$ and $45 \mathrm{deg}$.

We can observe that the difference between $G_{i c 1}$ and $G_{i c 2}$ simultaneously decreases as $\alpha$ increases. This result justifies that the two fracture modes are completely decoupled. This is also due to the fact that the value of the crack opening along $x$ and $y$ tend to be close to each other as $\alpha$ tends to $45 \mathrm{deg}$. Another interesting result is the fact that $G_{i c 1}$ decreases and $G_{i c 2}$ increases as $\alpha$ tends to $45 \mathrm{deg}$, which seems logical since the difference $G_{i c 1}-G_{i c 2}$ decreases. 


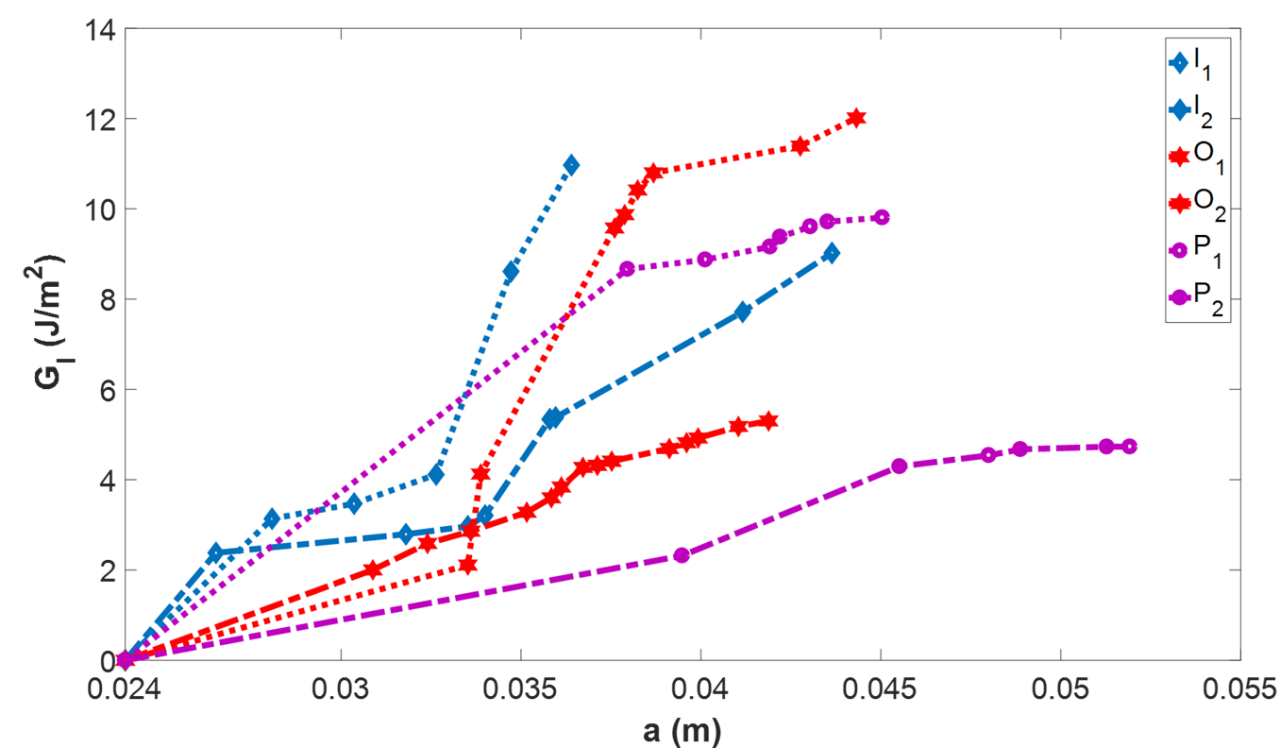

(a)

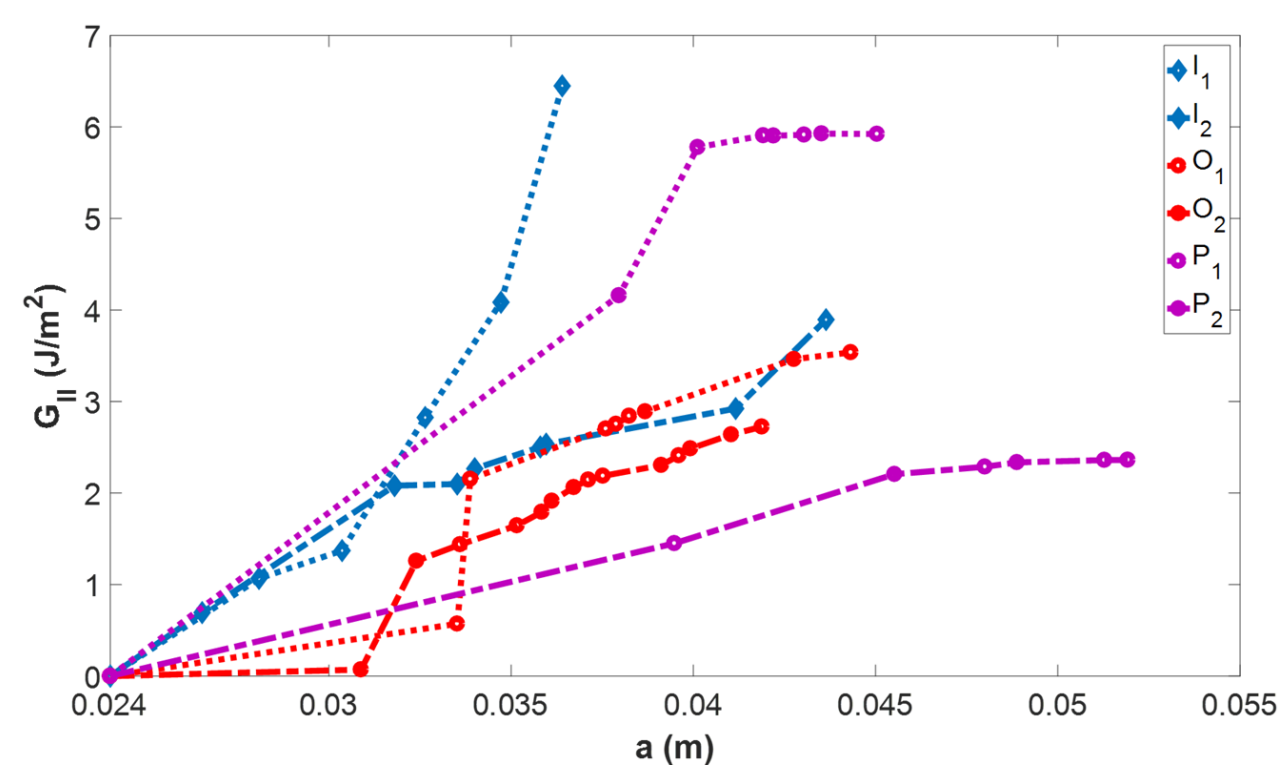

(b)

Figure 9: Critical energy release rate vs crack length for $\alpha=15$ deg. (a) part of mode I $\left(G_{I}\right)$.(b) part of mode II $\left(G_{I I}\right)$

The results presented here are scattered. This property is probably due to the specificity of tropical wood. Indeed, tropical species feature a fluctuation of the grain. Some of these species like okume have a slightly wavy thread. This certainly explains the high and sudden jumps of the energy release rate observed for specimens $O_{1}, O_{4}$ and $O_{7}$ in Figure 7-(b)), which shows typical displacement maps for okume. We can observe that for specimens $O_{1}$ and $O_{4}$, the crack has a slight inclination. In these two cases, the energy 


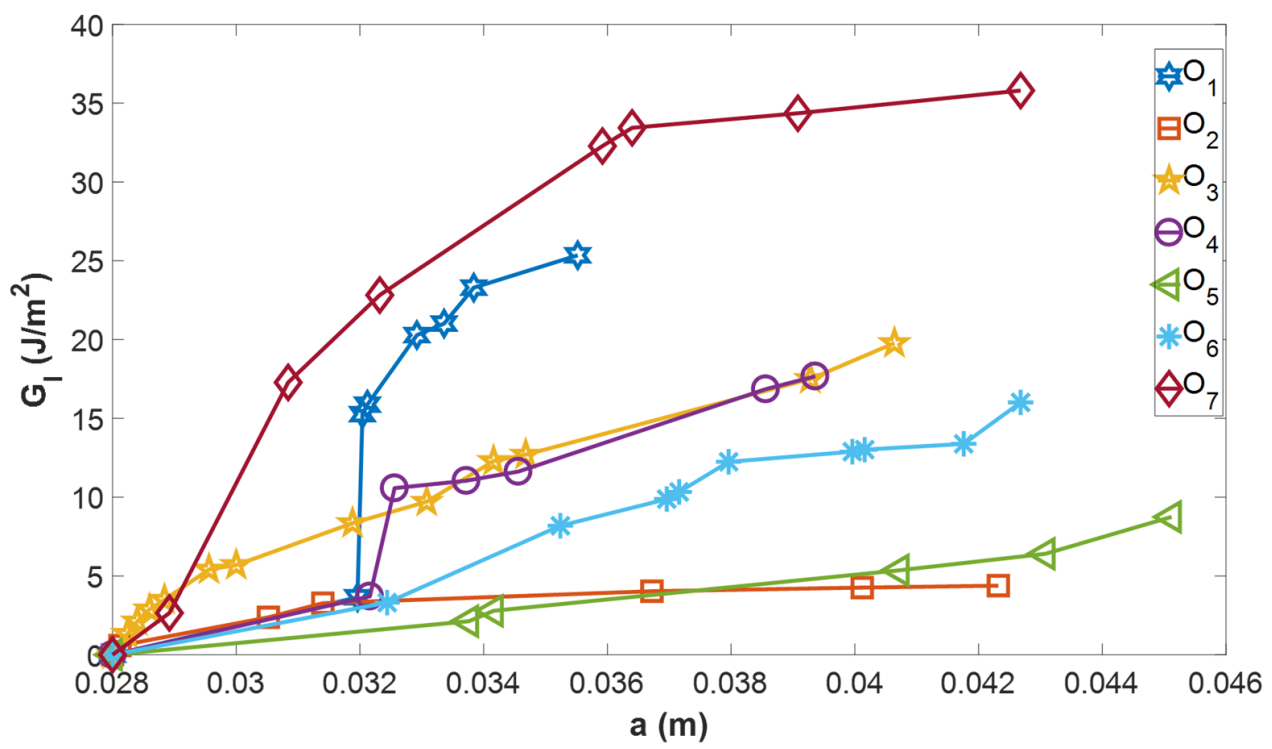

(a)

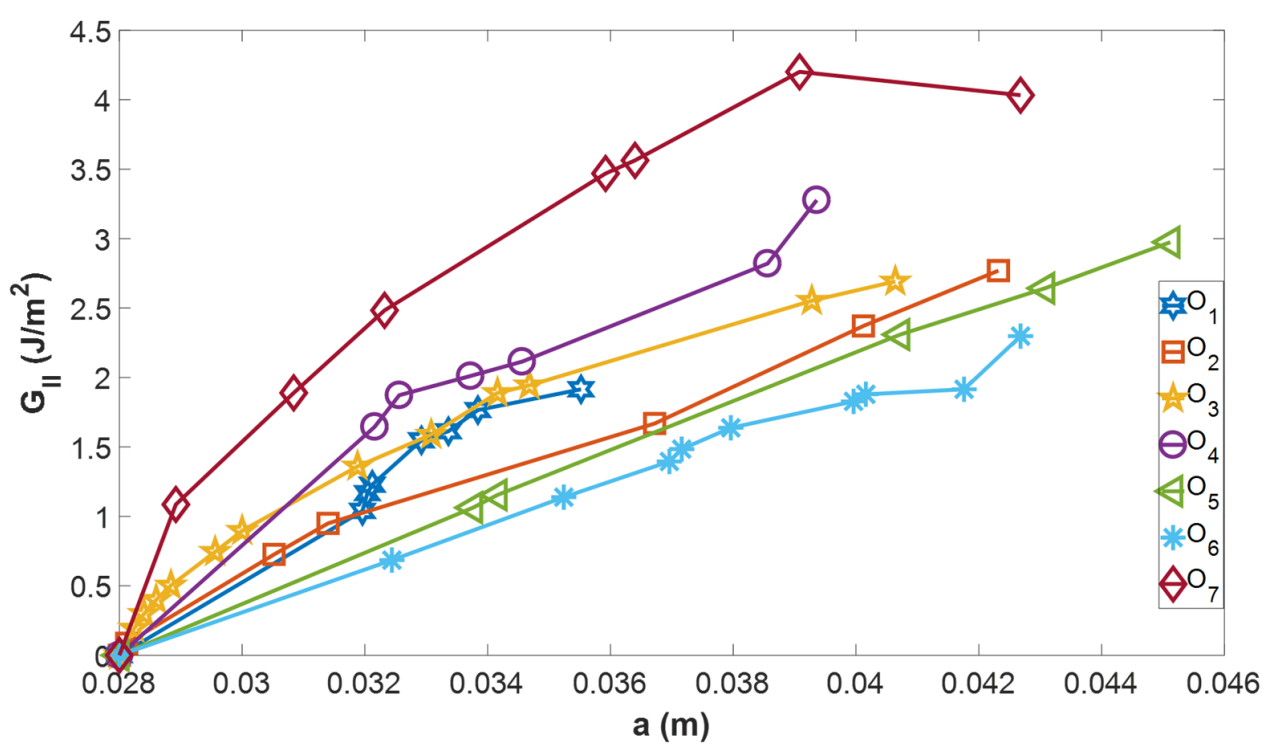

(b)

Figure 10: Critical energy release rate vs crack length for $\alpha=30$ deg. (a) part of mode I $\left(G_{I}\right)$.(b) part of mode II $\left(G_{I I}\right)$

release rate is greater than for a perfectly horizontal and straight crack propagation. It is worth noting that it is precisely with these particular specimens, which feature inclined cracks, that the energy release rate is the highest. In practice, it is however very difficult to align the direction of the crack with the direction of the grain because of the continuous growing of tropical species. 


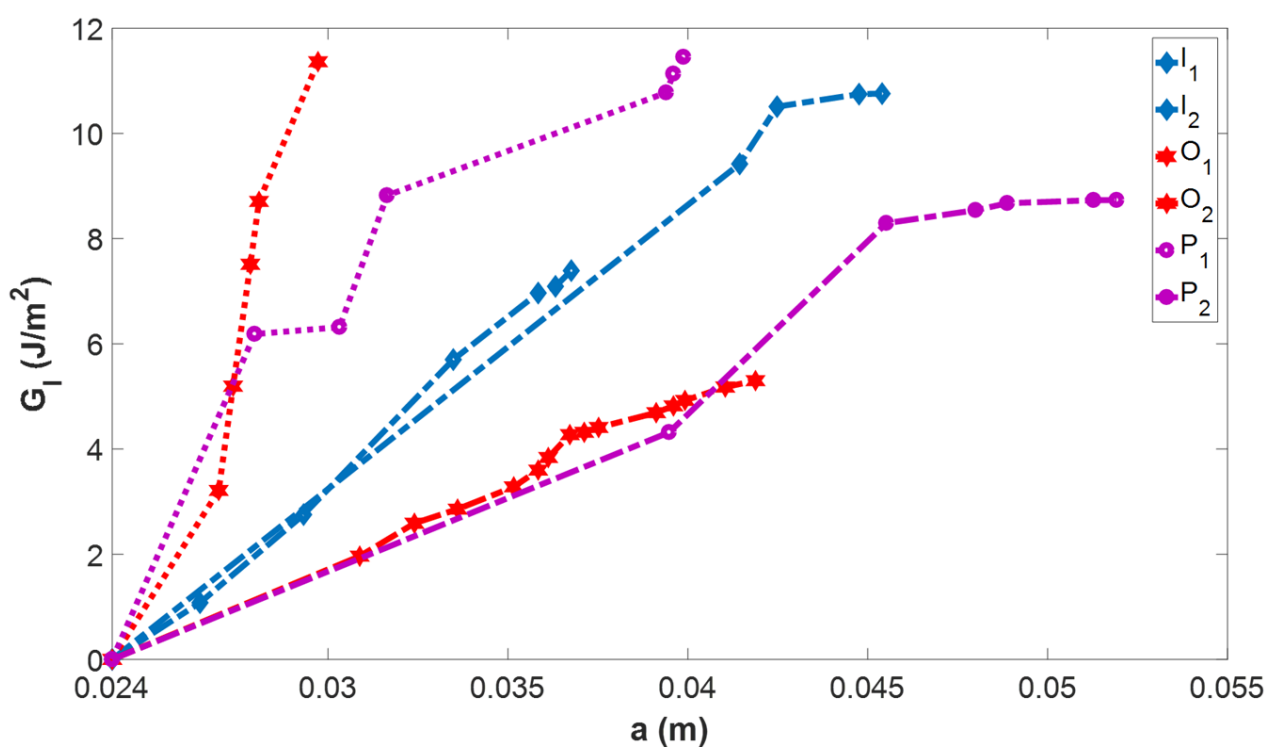

(a)

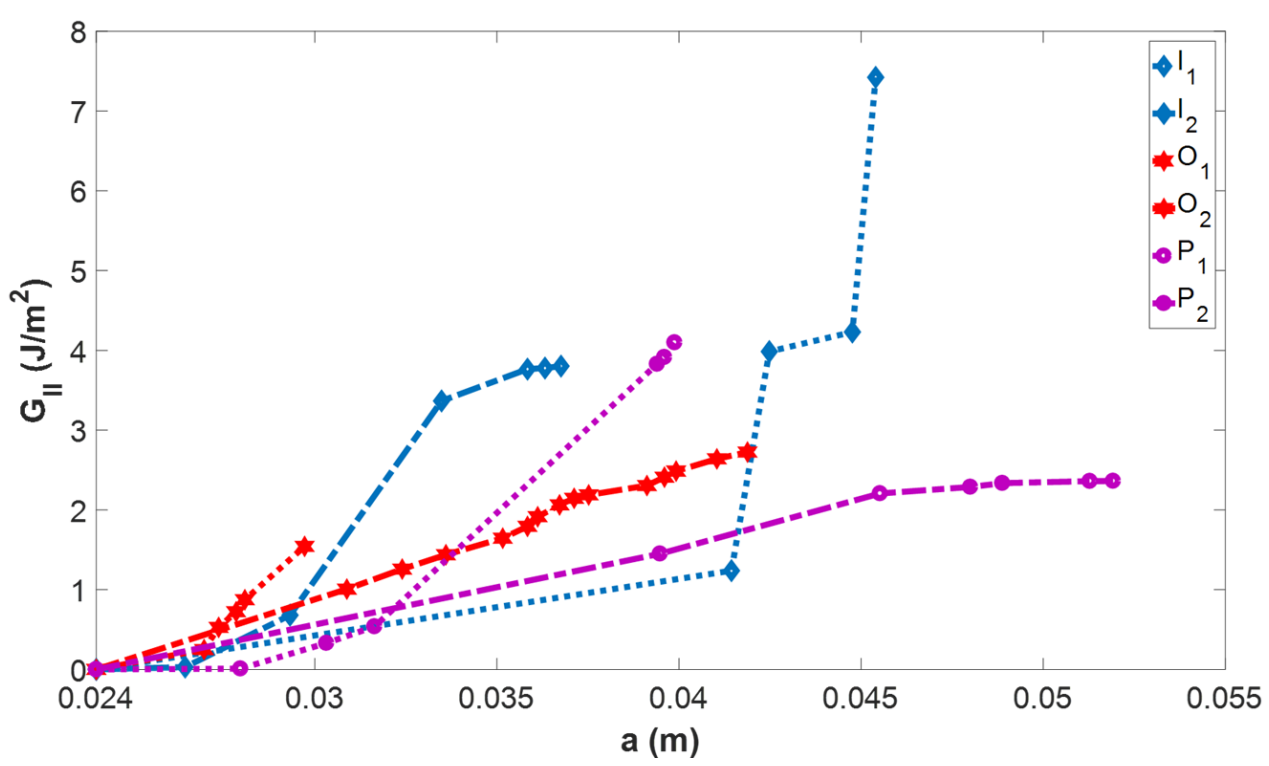

(b)

Figure 11: Critical energy release rate vs. crack length for $\alpha=45$ deg. (a) part of mode I $\left(G_{I}\right)$. (b) part of mode II $\left(G_{I I}\right)$

\section{Conclusion}

In this paper, small-sized MMCG specimens were used to study mixed mode cracking of iroko, okoume and padouk. An electromechanical testing machine was used to perform tensile tests for mixed mode ratios equal to $\alpha=15 \mathrm{deg}, 30 \mathrm{deg}$ and $45 \mathrm{deg}$. The grid method was used to measure the crack opening and the location of the crack tip. It is shown that it is possible to measure separately the energy release rate in opening mode 


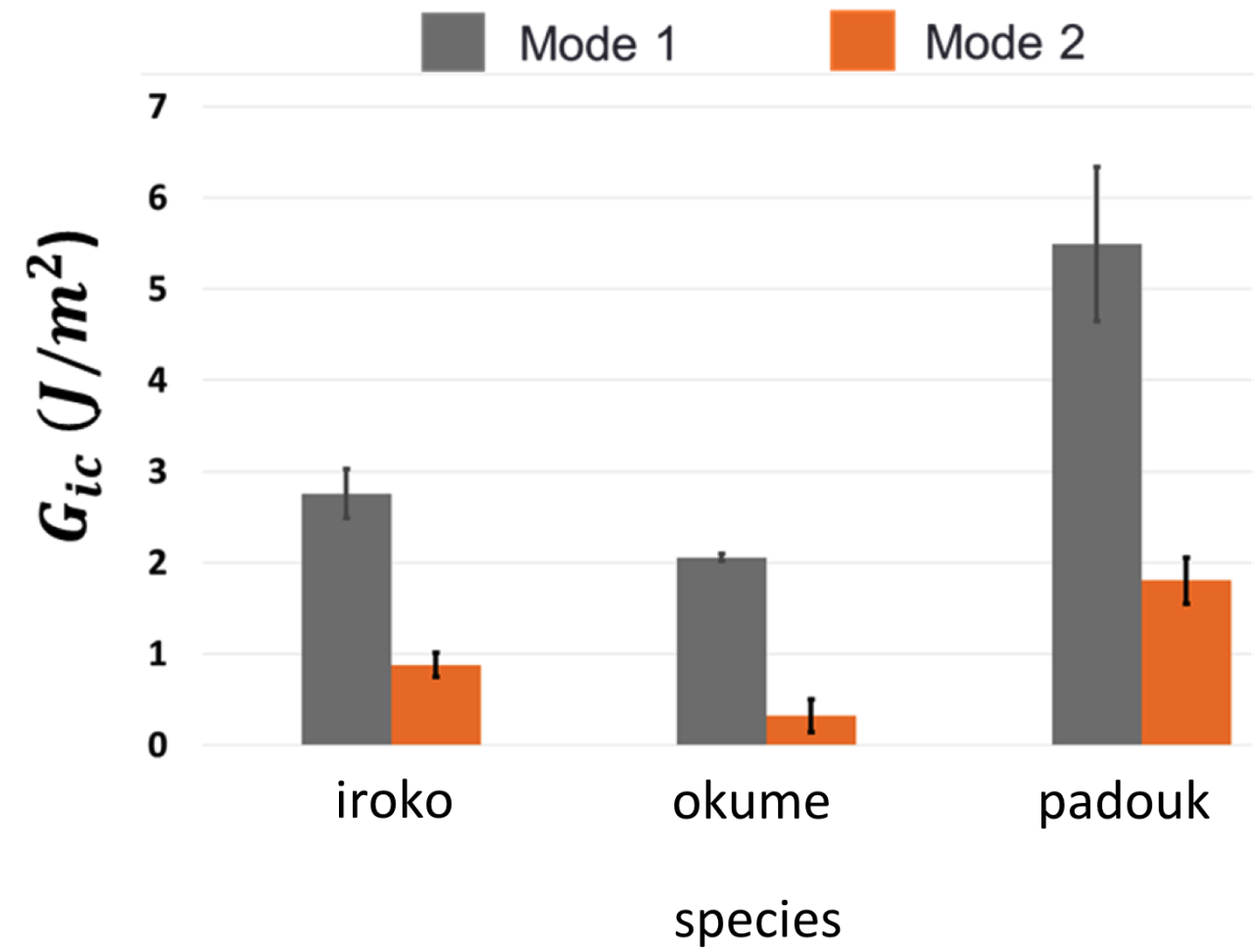

Figure 12: Minimum initial average values of the energy release rate $G_{i c}$ (with error bars): Part of mode I and II for specimens, $b=12.5 \mathrm{~mm}, \alpha=45 \mathrm{deg}$

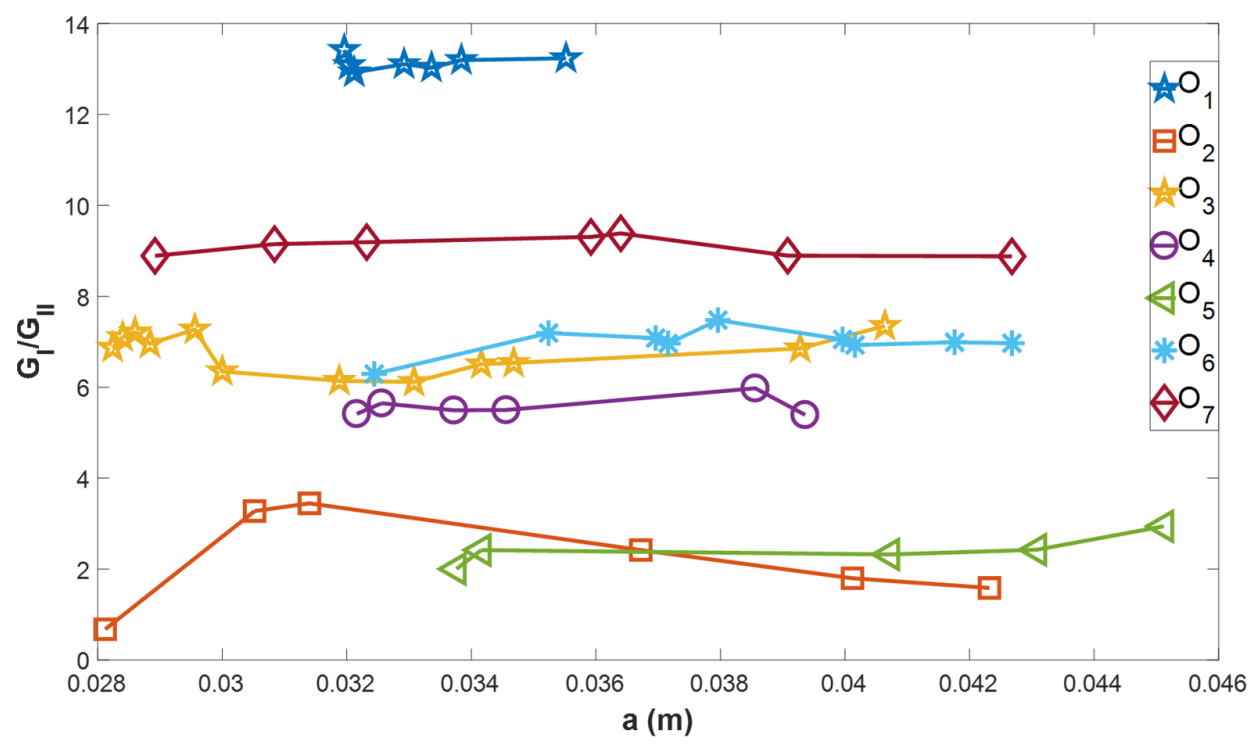

Figure 13: $G_{I} / G_{I I}$ ratio for okume, $\alpha=30 \mathrm{deg}$ and $b=15 \mathrm{~mm}$.

on the one hand, and in the shear mode on the other hand. The main observation is that for the tested specimens, $G_{I}$ is greater than $G_{I I}$. The results also show that there is an influence of the density on the fracture toughness of these species. In addition, the evolution of the $G_{I} / G_{I I}$ ratio as a function of the crack length was given for okoume. 
Table 3: Comparison of $G_{i c 1}$ and $G_{i c 2}$ of the three species.

\begin{tabular}{cccc}
\hline Designation & iroko & okume & padouk \\
\hline Thickness $15(15 \mathrm{deg})$ & $G_{i c 1}-G_{i c 2}=1.88$ & $G_{i c 1}-G_{i c 2}=1.70$ & $G_{i c 1}-G_{i c 2}=2.70$ \\
\hline & & $G_{i c 1}-G_{i c 2}=1.65$ & $G_{i c 1}-G_{i c 2}=2.40$ \\
Thickness 15 (30 deg) & & $G_{i c 1} / G_{i c 2}=3.00$ & \\
\hline Thickness 12.5 (45 deg) & $G_{i c 1}-G_{i c 2}=1.90$ & $G_{i c 1}-G_{i c 2}=0.70$ & $G_{i c 1}-G_{i c 2}=2.80$ \\
\hline
\end{tabular}

This ratio is nearly constant, which illustrates that the values obtained in this study are intrinsic values for this species. In future work, it would be interesting to study mixed mode ratios in variable environment and consider other specimen geometries in order to reach higher mixed mode ratios, as in [11] for tempered species. The maximum angle that can be reached with the Arcan fixture on such tropical species will also be investigated.

\section{References}

[1] Pambou Nziengui C. F., Ikogou S. and Moutou Pitti R. , Impact of cyclic compressive loading and moisture content on the mechanical behavior of aucoumea klaineana pierre, Wood Material Science \& Engineering 13 (4) (2018) 190-196.

[2] Pambou Nziengui C. F., Moutou Pitti R., Fournely E., Gril J., Godi G. and Ikogou S., Notched-beam creep of douglas fir and white fir in outdoor conditions: Experimental study, Construction and Building Materials 196 (2019) 659 - 671.

[3] Valentin G and Caumes P, Crack propagation in mixed mode in wood: a new specimen, Wood Science and Technology 23 (1) (1989) 43-53. doi:10.1007/BF00350606.

[4] Oliveira J. M. Q. , de Moura M. F. S. F., Silva M. A. L. and Morais J. J. L., Numerical analysis of the MMB test for mixed-mode I/II wood fracture, Composites Science and Technology 67 (9) (2007) 1764 - 1771. doi:https://doi.org/10.1016/j.compscitech.2006.11.007.

[5] Phan N. A., Morel S. and Chaplain M., Mixed-mode fracture in a quasi-brittle material: R-curve and fracture criterion applica- 
tion to wood, Engineering Fracture Mechanics 156 (2016) 96 - 113. doi:https://doi.org/10.1016/j.engfracmech.2016.02.006.

[6] Chen F. H. K. and Shield R. T., Conservation laws in elasticity of the j-integral type, Zeitschrift für angewandte Mathematik und Physik ZAMP 28 (1) (1977) 1-22. doi:10.1007/BF01590704.

[7] Moutou Pitti R., Dubois F., Petit C. and Sauvat N., Mixed mode fracture separation in viscoelastic orthotropic media: numerical and analytical approach by the $\mathrm{m} \theta \mathrm{v}$-integral, International Journal of Fracture 145 (3) (2007) 181-193. doi:10.1007/s10704-007-9111-4.

[8] Erna Susanti C. M., Nakao T. and Yoshihara H., Examination of the failure behaviour of wood with a short crack in the tangential radial system by singleedge-notched bending test, Engineering Fracture Mechanics 77 (13) (2010) 2527 $-2536$.

[9] Jernkvist L. O., Fracture of wood under mixed mode loading: I. Derivation of fracture criteria, Engineering Fracture Mechanics 68 (5) (2001) 549-563. doi:https://doi.org/10.1016/S0013-7944(00)00127-2.

[10] Anaraki A. R. G. and Fakoor M., General mixed mode I/II fracture criterion for wood considering T-stress effects, Materials \& Design 31 (9) (2010) 4461-4469. doi:https://doi.org/10.1016/j.matdes.2010.04.055.

[11] R. Moutou Pitti and F. Dubois and O. Pop, A proposed mixed-mode fracture specimen for wood under creep loadings, International Journal of Fracture 167 (2) (2011) 195-209.

[12] R. Moutou Pitti and A. Chateauneuf, Statistical approach and reliability analysis for mixed-mode applied to wood material, Wood Science and Technology 46 (6) (2012) 1099-1112.

[13] Aicher S., Ahmad Z. and Hirsch M., Bondline shear strength and wood failure of european and tropical hardwood glulams, European Journal of Wood and Wood Products 76 (4) (2018) 1205-1222. 
[14] Odounga B., Moutou Pitti R., Toussaint E. and Grédiac M., Mode I fracture of tropical woods using grid method, Theoretical and Applied Fracture Mechanics 95 (2018) 1-17.

[15] Fahn A., Burley J., Longman K. A., Mariaux A. and Tomlinson P. B., Possible contributions of wood anatomy to the determination of the age of tropical trees, Age and growth rate of tropical trees: new directions for research Bull. School For., Yale Univ 94 (1981) 31-54.

[16] Alvim, P. T., Tree growth periodicity in tropical climates, the formation of wood in forest trees. academic press (1964).

[17] Odounga B., Moutou Pitti R., Toussaint E. and Grédiac M., Experimental fracture analysis of tropical species using the grid method, in: Fracture, Fatigue, Failure and Damage Evolution, Springer 8, 2017, pp. 9-14.

[18] Merakeb, S., Modélisation des structures en bois en environnement variable, Ph.D. thesis, Université de Limoges, 46 (2006).

[19] CIRAD, Agricultural research for development (1998) tropical specie reports. tropix 7-c (1998-2011).

[20] Piro J.-L. and Grédiac M., Producing and transferring low-spatial-frequency grids for measuring displacement fields with moiré and grid methods, Experimental Techniques 28 (4) (2004) 23-26, society for Experimental Mechanics.

[21] Grédiac M., Sur F. and Blaysat B., The grid method for in-plane displacement and strain measurement: a review and analysis, Strain 52 (3) (2016) 205-243.

[22] Moutou Pitti R., Badulescu C. and Grédiac M., Characterization of a cracked specimen with full-field measurements: direct determination of the crack tip and energy release rate calculation, International Journal of Fracture 187 (1) (2014) 109-121, springer.

[23] Grédiac M., Blaysat B. and Sur F., A critical comparison of some metrological parameters characterizing local digital image correlation and grid method, Experimental Mechanics 57 (3) (2017) 871-903. 